\title{
Mesothelioma of the atrioventricular node
}

\author{
KENJI NISHIDA, „ GONBEI KAMIJIMA, * TADASHI NAGAYAMA† \\ From the ${ }^{*}$ Second Department of Internal Medicine and the + Department of Pathology, Toho University School of \\ Medicine, Tokyo, Japan
}

SUMMARY A patient with Mobitz type 2 heart block caused by a mesothelioma of the atrioventricular node died of a subarachnoid haemorrhage at the age of 33 two years after implantation of a permanent pacemaker. Mesothelioma of the atrioventricular node is rare, and reported cases have all been diagnosed post mortem. Mesothelioma of the atrioventricular node should be considered in the differential diagnosis of heart block in children or young adults. This is the first case to be reported in Japan.

\section{Case report}

A 31 year old man was admitted to hospital because of poor appetite. On routine physical examination, a grade $2 / 6$ systolic murmur was heard at the left sternal border. No cyanosis was noted. The liver was not palpable. Serum aspartate aminotransferase and alanine aminotransferase activities were $58 \mathrm{U} / 1$ and 29 $\mathrm{U} / 1$ respectively. A liver biopsy showed a cirrhotic pattern, and he was diagnosed as having alcoholic cirrhosis.

At night his heart rate fell to 30 beats $/ \mathrm{min}$, and an electrocardiogram showed 2:1 atrioventricular block with a narrow $Q R S$ complex (Fig. 1). His bundle electrograms were recorded using standard catheter techniques. The $\mathrm{HV}$ interval was normal $(30 \mathrm{~ms})$ and the AH interval prolonged $(150 \mathrm{~ms})$. The echocardiogram was normal. Four weeks later a permanent pacemaker was implanted. Exactly a year later he was readmitted to hospital because of sudden headache and vomiting. On examination his pulse was 72 beats $/ \mathrm{min}$ and blood pressure $136 / 86 \mathrm{~mm} \mathrm{Hg}$. He was disorientated and there was no neck stiffness. No other neurological abnormalities were present. Computed tomography was performed immediately after admission and showed high density areas in the frontal lobe, lateral ventricles, and subarachnoid space. During the examination he had an episode of apnoea and became deeply comatose. A carotid angiogram showed an aneurysm of the left anterior cerebral artery, and subarachnoid haemorrhage due to a ruptured aneurysm was diagnosed. The patient underwent mechanical ventilation but died on the ninth day after admission.

Requests for reprints to Dr Kenji Nishida, 2nd Department of Internal Medicine, Toho University School of Medicine, 6-11-1 Ohmori Nishi Ohtaku Tokyo, Japan.

\section{NECROPSY FINDINGS}

The postmortem examination was performed only 16 minutes after death and confirmed an extensive subarachnoid haemorrhage. A ruptured aneurysm of the left pericallosal artery was found. The brain weighed $1.735 \mathrm{~kg}$, which was compatible with so called "respirator brain." The heart weighed $340 \mathrm{~g}$; there was no abnormality in the epicardium, the endocardium, or the valves. The myocardium showed previous and recent ischaemic changes with patchy fibrosis. The coronary arteries were moderately atherosclerotic. The serial sections of the cardiac conduction system showed a small ill defined tumour approximately $1 \mathrm{~cm}$ in diameter in the atrioventricular node. Histological sections of the atrioventricular node area showed a benign tumour, a so called mesothelioma consisting of tubular and cyst like structures of varying sizes and fibrous stroma. The tubular and cyst like structures were lined by either single or multiple layers of cuboidal or squamous epithelial cells (Fig. 2). In the lumens and cysts there was amorphous eosinophilic material, which showed strongly positive results when tested with periodic acid Schiff staining and was weakly positive with alcian blue staining. In some areas the lining cells appeared to be stratified squamous epithelium, but there were no apparent intercellular bridges nor keratin material. In the fibrous stroma there were a few chronic inflammatory cells. There was a moderate degree of fibrosis in the sinoatrial node region.

\section{Discussion}

Cardiac tumours are rare, and mesothelioma of the atrioventricular node is a very uncommon cause of congenital heart block and sudden death. It has been 

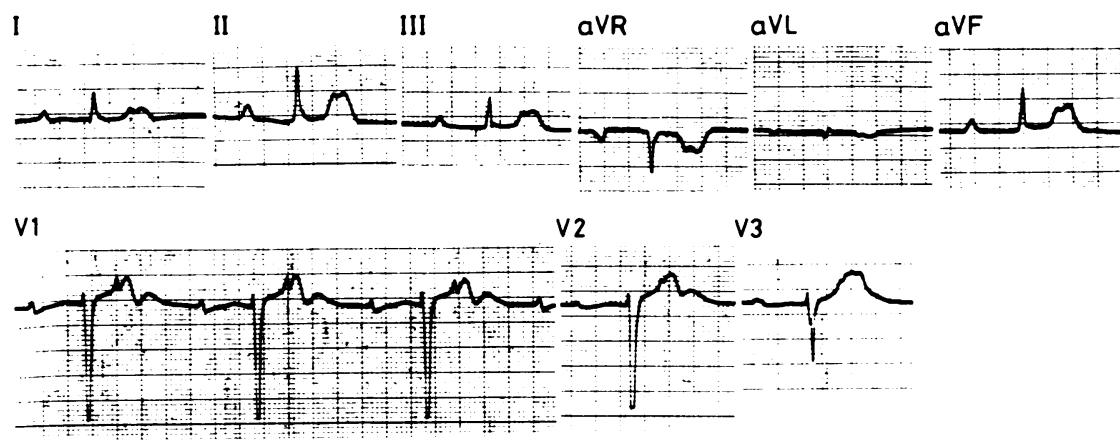

Fig. 1 Electrocardiogram showing second degree (2:1) atrioventricular block and a ventricular rate of 44 beats/min.

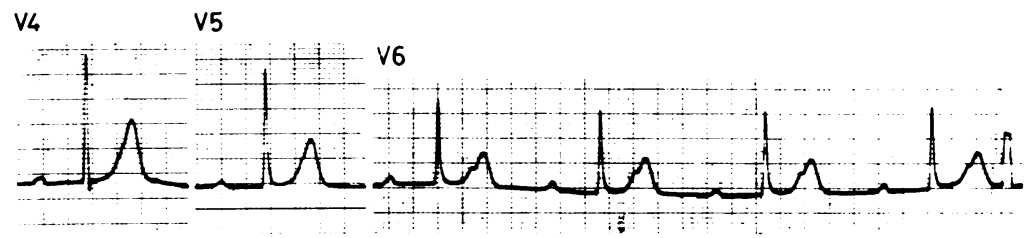

recognised, however, as "the smallest tumour which causes sudden death." Mönckeberg described the first case of this type in 1911 in a 5 year old boy, ${ }^{2}$ about 50 cases have been reported. ${ }^{3-5}$ The ages of the patients range from eight months' gestation to 86 years with more females affected than males. ${ }^{6-8}$ Our case is the first report of a mesothelioma of the atrioventricular node in Japan. Most reported cases have been in patients aged $<40$ years at the time of death. The cause of sudden death is probably ventricular tachycardia or ventricular fibrillation. Permanent pacemaker implantation did not prevent sudden death in some reported cases. ${ }^{9-11}$

In the present case, a permanent pacemaker was implanted in the right ventricle, but the patient died of subarachnoid haemorrhage. Two similar cases in which the patient died of a cerebrovascular accident have been reported previously! ${ }^{1213}$; nevertheless, the relation between cerebrovascular accident and atrioventricular node mesothelioma is unknown. The Mobitz type 2 atrioventricular block may conceivably have been incidental in this case because moderate coronary atherosclerosis was found at necropsy. Causes of death, other than arrhythmias, have been

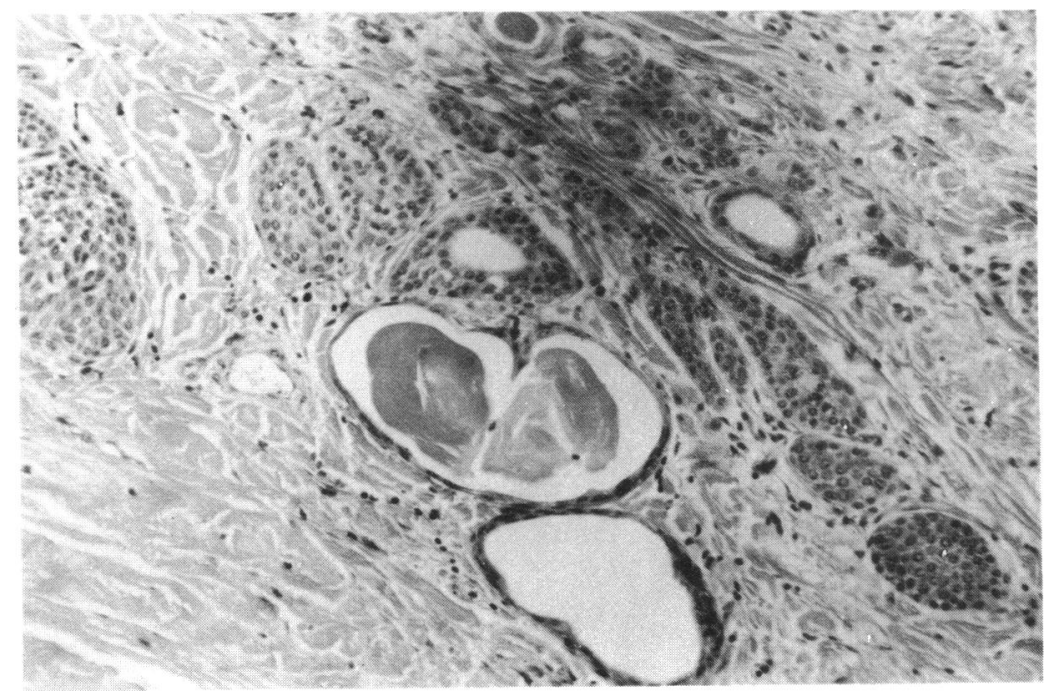

Fig. 2 Histological appearance of a tumour consisting of cyst like and tubular formations lined by one or several layers of flat or cuboidal mesothelia like cells. In some cysts eosinophilic material is also present. (Haematoxylin and eosin, $\times 200$ original magnification.) 
identified only rarely in patients with this lesion ${ }^{12-14}$ and no cases have been diagnosed during life. Nevertheless, Bharati et al suggested that it may be diagnosed clinically by selective coronary arteriography. ${ }^{15}$ The blood supply of the atrioventricular node and common bundle is derived from the atrioventricular nodal artery, which is a branch of the right coronary artery in nine out of 10 cases. Thus they considered that the lesion could be diagnosed if findings indicating a tumour or an abnormality of the atrioventricular nodal artery were found. We agree with this opinion, but we do not consider that permanent pacemaker implantation is lifesaving because patients usually die of ventricular tachyarrhythmias. Antemortem diagnosis is difficult; nevertheless, a mesothelioma of the atrioventricular node should be considered in the differential diagnosis of heart block in children or young adults.

\section{References}

1 Wolf PL, Bing R. The smallest tumour which causes sudden death. $\mathcal{F A M A} 1965 ; 194: 674-5$.

2 Armstrong H, Mönckeberg JG. Herzblock bedingt durch primären Hertztumor, bei einem 5 jährigen Kinde. Deutsches Archiv für Klinische medizin 1911; 102: $144-66$.

3 Koojiman CD. Mesothelioma of the atrioventricular node, a rare tumour, capable of causing sudden death. Tijd Kindergeneeskd 1980; 48: 172-5.
4 Lie JT, Luftschanowski R, Erickson EE. Heterotopic epithelial replacement (so called "mesothelioma") of the atrioventricular node, congenital heart block, and sudden death. Am 7 Forensic Med Pathol 1980; 1: 131-7.

5 Case records of the Massachusetts general hospital (case 1-1982). N Engl f Med 1982; 306: 32-9.

6 Morris AW, Johnson IM. Epithelial inclusion cysts of the heart. Arch Pathol 1964; 77: 36-40.

7 Manion WC, Nelson WP, Hall RJ, Brierty RE. Benign tumor of the heart causing complete heart block. Am Heart f 1972; 83: 535-42.

8 Case records of the Massachusetts general hospital (case 6-1973). N Engl f Med 1973; 288: 308-15.

9 Hopkinson JM, Newcombe CP. Heart block due to epithelial heterotopia. F Pathol 1971; 104: 218-20.

10 Lafargue RT, Hand AM, Lev M. Mesothelioma (coelothelioma) of the atrioventricular node. Chest 1971; 59: $571-4$.

11 Lewman LV, Demany MA, Zimmerman HA. Congenital tumor of atrioventricular node with complete heart block and sudden death. Am f Cardiol 1972; 29: 554-7.

12 David R, Hiss Y. Corpora amylacea in mesothelioma of the atrioventricular node. F Pathol 1977; 124: 111-6.

13 Rossi L. Case of cardiac lymphangitis with atrioventricular block. Br Med F 1965; ii: 32-3.

14 James TN, Galakhov I. Fatal electrical instability of the heart associated with benign congenital polycystic tumor of the atrioventricular node. Circulation 1977; 56: 66778.

15 Bharati S, Bicoff JP, Fridman JL, Lev M, Rosen KM. Sudden death caused by benign tumor of the atrioventricular node. Arch Intern Med 1976; 136: 224-8. 